\title{
Fontes para uma sócio-história linguística do português popular: as cartas de mãos inábeis do sertão baiano
}

\author{
Sources for a social history linguistics of the popular Portuguese language: the letters of \\ unable hands from Babian binterland \\ Huda da Silva Santiago* \\ Universidade Estadual de Feira de Santana, Bahia, Brasil \\ Zenaide de Oliveira Novais Carneiro** \\ Universidade Estadual de Feira de Santana, Bahia, Brasil
}

\begin{abstract}
Resumo: Neste texto, apresentam-se algumas reflexões sobre o corpus constituído por cartas pessoais escritas por sertanejos da zona rural do semiárido baiano, ao longo do século XX, disponibilizado em Santiago (2012). Essas cartas, uma amostra representativa da vertente popular do português brasileiro, permitem evidenciar a recorrência à prática da escrita por redatores com baixo nível de letramento: o afastamento das normas gramaticais e ortográficas percebido nos textos indica que tiveram pouco contato com os modelos normativos prescritos pela escola. Para o reconhecimento de produtos gráficos desse tipo, elaborados em níveis incipientes de aquisição da escrita, pode ser realizado o controle de algumas marcas de inabilidade em escrita alfabética, distribuídas em vários planos. Essa é uma documentação rara, tanto para os estudos histórico-diacrônicos do português brasileiro, no que se refere à linguística de corpus, como para os estudos, em um âmbito mais específico, da História da Cultura Escrita, reconhecendo-se a importância da localização de textos que sejam reflexo de uma escrita cotidiana, produtos de mãos inábeis, que apresentem dados mais próximos do vernáculo, de grupos sociais que tiveram pouco acesso à escolarização.
\end{abstract}

Palavras chave: Português popular brasileiro. Cartas pessoais. Mãos inábeis.

\begin{abstract}
In this text, we present some reflections about the corpus formed by personal letters written by sertanejos from the rural semi-arid area in Bahia, throughout the 20th century, in Santiago (2012). These letters, a representative sample of popular Brazilian Portuguese, allow the recurrence to the practice of writing by writers with low-level literacy: the removal of the grammatical and orthographic standards perceived in the texts indicates that they had little contact with the normative models prescribed by the school. For the recognition of such elaborate graphics products in incipient levels of acquisition of writing, an accomplished control of some unable hands to alphabetic writing, distributed in several plans can be perceived. This is a rare documentation, both for the historical and diachronic studies of Brazilian Portuguese as regards to linguistic corpus, as for studies in a more specific context in the History of Written Culture, recognizing the importance of the localization of texts that are reflective of everyday writing, by products made by unable hands, which present data closer to the vernacular, of social groups that had little access to education.
\end{abstract}

Keywords: Popular Brazilian Portuguese. Personal letters. Unable hands.

\section{INTRODUÇÃO}

Seja para os estudos sócio-históricos do português brasileiro, no que se refere à linguística de corpus, ou para os estudos, em um âmbito mais específico, da História da Cultura Escrita, a constituição de corpora diacrônicos com textos não literários, mais próximos da escrita cotidiana, vernacular, tem sido uma tarefa necessária e desafiadora.

Para a constituição sócio-histórica da língua, sabe-se que os documentos escritos são o material empírico para o estudo de sincronias passadas, considerando-se a impossibilidade de acesso à fala dos indivíduos dessas sincronias; pode-se, apenas, como lembra Mattos e Silva (2008, p. 20), “[...] entrever ou entreouvir a voz através dos textos: tarefa difícil e apenas aproximativa, 'ouvir o inaudível”', alertando que sem a fala não se escreve. Nesse sentido, os

* Estudante de doutorado, professora do Departamento de Letras e Artes, da Universidade Estadual de Feira de Santana. E-mail: huda.santiago@hotmail.com.

** Professora doutora do Departamento de Letras e Artes, da Universidade Estadual de Feira de Santana. E-mail: zenaide.novais@gmail.com. 
textos mais transparentes na escrita, em relação aos dados da oralidade, aqueles produzidos por mãos pouco hábeis em escrita alfabética, tem especial valor. Para Barbosa (2008, p. 183), é preciso descobrir fontes escritas mais transparentes, com índices que reflitam um pouco melhor certos traços de oralidade, seja pela inabilidade/desconhecimento, por parte dos redatores, de fórmulas textuais, seja pela relação simétrica de poder entre remetente e destinatário, seja ainda pelo caráter intimista de um dado tema.

Para a História da Cultura Escrita, é fundamental visibilizar as práticas de escrita de pessoas comuns, os produtos gráficos de grupos sociais situados à margem da história oficial, como lembra Petrucci (2000). Em relação aos redatores que escreveram mesmo sem o total domínio da habilidade de escrita, as informações sobre o seu perfil sociocultural contribuem para elucidar questões sobre os processos de letramento que possibilitaram os seus textos e sobre a difusão da escrita em determinado espaço/tempo.

A amostra constituída por cartas pessoais de sertanejos baianos, escritas ao longo do século XX, atende a essas motivações. Os redatores possuem pouca escolarização - a maioria teve contato com as primeiras letras em espaços extraescolares - e evidenciam a pouca familiaridade com a escrita em textos que apresentam marcas de inabilidade em escrita alfabética em vários planos; os manuscritos são, então, produtos de mãos inábeis, expressão consagrada por Marquilhas (2000) para designar os autores estacionados em níveis incipientes de aquisição da escrita. Esse é um corpus representativo: as cartas foram trocadas em relação de simetria entre redatores que fazem parte de um contexto sociocultural semelhante e são textos próximos de uma escrita cotidiana, de caráter afetivo, apresentando um significativo grau de transparência aos usos vernáculos.

\section{SOBRE O CORPUS}

Diante do desafio para a reconstrução do português popular brasileiro, em que se evidencia a necessidade de buscar a produção escrita cotidiana, daqueles pertencentes a classes sociais inferiores, que tiveram pouco acesso à escolarização, Oliveira (2009, p. 175) questiona: "[...] onde encontrar fontes que podem ser de serventia para uma história do português popular brasileiro?”.

Alguns trabalhos têm mostrado ser possível encontrar produtos gráficos de indivíduos pertencentes às classes subalternas, como, por exemplo, a localização e a edição, por esse mesmo pesquisador, de 290 atas escritas por africanos e afrodescendentes na Bahia oitocentista. São documentos inéditos, uma amostra relevante para evidenciar a escrita dos negros na Bahia ao longo do século XIX, cujo um dos méritos é, de acordo com o próprio autor, em face de um corpus geral diacrônico para o estudo da constituição histórica do português brasileiro, "[...] consentir aproximações do que teria sido o português popular do passado [...]” (OLIVEIRA, 2006, p. 213).

Uma amostra que apresenta semelhante especificidade é a constituída de 91 cartas pessoais escritas ao longo do século XX - uma maior quantidade correspondente às décadas de 50,60 e 70 - por 43 sertanejos oriundos da zona rural do semiárido baiano, dos municípios de Riachão do Jacuípe, Conceição do Coité e Ichu, cuja edição é disponibilizada no volume II da dissertação Um estudo do português popular brasileiro em cartas pessoais de 'mãos cândidas' do sertão baiano (SANTIAGO, 2012).

A edição dessas cartas, nas versões semidiplomática e modernizada, faz parte do acervo do banco Corpus Eletrônico de Documentos Históricos do Sertão - CE-DOHS (www.uefs.br/cedohs), do Projeto Vozes do Sertão em Dados: história, povos e formação do Português Brasileiro (CNPq. 401433/2009-9), um dos projetos do Núcleo de Estudos em Língua Portuguesa - NELP, da Universidade Estadual de Feira de Santana. 
Os critérios para a edição semidiplomática, conservadora, foram elaborados com base nas normas de transcrição para documentos manuscritos do Projeto Para a bistória do português brasileiro (MATTOS E SILVA, 2001). O processo de transcrição foi feito com base em fotos digitais sem flashs, obtidas dos documentos originais.

A identificação de algumas marcas de inabilidade em escrita alfabética, em vários planos, nesses textos, permite perceber que os redatores têm pouco domínio da técnica de escrita. Para essa identificação, tem-se por base os critérios estabelecidos para corpora de inábeis já estudados, como os definidos por Marquilhas (2000), para os manuscritos portugueses, do século XVII, do arquivo da Inquisição; por Barbosa (1999), para as cartas de comércio do século XVIII, de indivíduos pouco hábeis no Brasil colonial, e por Oliveira (2006), para as atas escritas por africanos e afrodescendentes na Bahia, no século XIX. A seguir, uma das cartas dos sertanejos:

Figura 1 - Carta 1 AJCO. Documento contendo um fólio. Papel almaço com pautas.

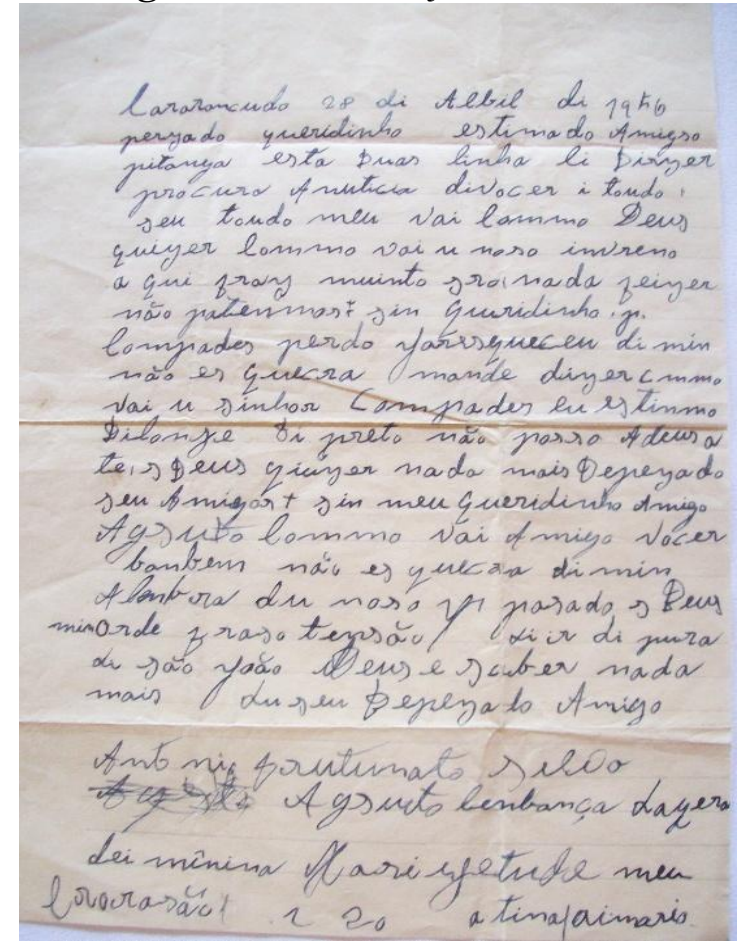

Cararancudo 28 di Albil di 1956|

perzado queridinho estimado Amigso| pitanga esta Duas linha li Dirzer| procura A nuticia divocer i toudo | seu toudo meu vai commo Deus| quizer commo vai u noso invreno | a qui frais muinto sro. nada feizer| não patenmos sin queridinho. p.| compades perdo jasesqueceu di min $\mid$ não es quecra mande dizer $\mathrm{cmmo}$ | vai u sinhor compader eu estinmo $\mid$ Dilonje Di preto não posso Adeus a| te, se Deus qiuzer nada mais Depezado seu Amigor sin meu queridinho Amigo| Agsuto commo vai Amigo vocer| banbem não es quec[.] a di min| Alenbra du noso [?] pasado se Deus| min orde fraso tensão di ir di pura| di são João Deus e saber nada| mais du seu Depezado Amigo|

Antonio frutunato silva|

Agste Agsuto lenbança daqera|

dei mênina Mari Jetude meu |

Crorasão [?] a tina aimario|

Fonte: CE-DOHS.

Algumas propriedades identificadas se referem aos aspectos paleográficos e supragráficos, como ausência de cursus; uso de módulo grande; ausência de regramento ideal; traçado inseguro; letras com aparência desenquadrada; rigidez e falta de leveza do conjunto; irregularidade da empaginação, e letras monolíticas. Do ponto de vista metodológico, há possibilidades de se reconhecer esses produtos gráficos a partir de sua aparência física, ou seja, da caligrafia da mão e das particularidades do suporte, como demonstra Marquilhas (2000) para os documentos portugueses, mesmo não sendo raros os casos em que há inversão entre essa aparência e o nível ortográfico. Entende-se que nem sempre esses aspectos físicos do desempenho caligráfico são suficientes para a identificação de textos de pessoas com pouca habilidade de escrita (BARBOSA, 1999, p. 158).

Tais propriedades foram testadas no corpus dos sertanejos baianos (cf. SANTIAGO, 2012), de modo que, associadas a outras, contribuem para a caracterização das mãos pouco exercitadas em escrita. Há várias cartas, como a ilustrada na Figura 1, que exibem características caligráficas que podem ser atribuídas à falta de habilidade com a técnica da escrita, mas há outras que apresentam uma caligrafia mais cuidada e só a presença de outras 
marcas próprias àqueles que se encontram em fase de aquisição da escrita é que indicará a inabilidade do redator. Muitas vezes, apenas o cruzamento de várias propriedades pode garantir a identificação dos níveis de inabilidade que cada mão apresenta. A seguir, alguns exemplos de aspectos identificados no corpus:

a) Segmentação gráfica não convencional: nota-se a dificuldade dos redatores em interpretar as fronteiras das palavras, de modo que as grafias hipersegmentadas, no exemplo (01), ou hipossegmentadas, em (02), que correspondem à inserção ou não do espaço em branco, respectivamente, parecem ser baseadas na percepção da fala ou nas próprias experiências anteriores com o código escrito.

(01) “uma Pequenna Caza primcipiada e não a cabada um Ser cadinho" (AML-81)

(02) "compades perdo jasesqueceu di min não es quecr" (AFS-1)

b) Aspectos relacionados à escriptualidade: alguns aspectos da linguagem escrita oferecem maior dificuldade para aqueles que estão nos estágios iniciais da aquisição, como a grafia de sílabas complexas envolvendo as consoantes líquidas, /r/ e /1/, e a sibilante, /s/, exemplificadas em (03); a representação da nasalidade, com dados que apresentam uma representação exagerada e outros com uma ausência dessa representação, como em (04), e a grafia dos dígrafos, em (05). Nota-se ainda, a presença de uma "representação deslumbrada da escrita", pois, para Marquilhas (2000, p. 237), o "deslumbramento" do inábil com a língua escrita faz com que os redatores busquem algumas soluções gráficas distantes das regularidades, percebidas, principalmente, nas grafias irregulares com o $<\mathrm{r}>$, mas também envolvendo o $<\mathrm{l}>$ e o $<$ s $>$, como ilustram os dados em (06).

(03) lenbarnsa por lembranca (AFS-5); estada por estrada (AFS-9); apreto por aperto (SFS40); pedão por perdão (RAC-90); ato por alto (FPS-47); almavi por amável (AFS-18); eteve por esteve (AHC-61).

(04) vanmos por vamos (AFS-2); commader por comadre (FP-79); Romaci por romance (JMA64); mado por mando (VAN-86).

(05) piqenno por pequeno (AFS-19); entrege por entregue (MC-36); coreios por correios (AFS7); nosa por nossa (AFS-7); trabalo por trabalho (JS-62); teno por tenho (VAN-86); Riacão por Riachão (ACO-44).

(06) şanetra por caneta (JS-62); dervo por devo (AFS-6), pargar por pagar (AFS-12); jar por já (LFO-32), lar por lá (ROM-73); salbi por sabe (AFS-4); caspital por capital (AFS24).

c) Escrita fonética: a transferência de traços próprios da oralidade para a escrita foi constatada nas mãos de todos os redatores. Alguns traços mais gerais, que não são tão específicos dos inábeis, como a elevação das vogais médias pretônicas e postônicas, em (07), e a apócope de /R/ em final de verbos no infinitivo, em (21); e outros mais raros, estigmatizados, como a prótese, em (17), e a aférese, em (19).

(07) Elevação de vogais médias pretônicas e postônicas: sigundo por segundo (AHC-54); nuvidadi por novidade (JMS-66); saudadi por saudade (FP-78); adoru por adoro (JMA64).

(08) Abaixamento das vogais altas em posição pretônica: Destinto por distinto (SFS-40), corzeiro por cruzeiro (AFS-3).

(09) Anteriorização de vogais: esmerinda por Almerinda (SFS-40).

${ }^{1}$ A identificação dos exemplos é realizada, ao longo do texto, com a indicação da sigla do remetente, seguida do número da carta. A sigla e a numeração correspondem àquelas que são apresentadas na edição dos documentos (cf. SANTIAGO, 2012 ou CARNEIRO; SANTIAGO; OLIVEIRA, 2011). 
(10) Posteriorização de vogais: tombem por também (VAN-86).

(11) Redução de ditongos: importansa por importancia (AFS-4), esteji por estejam (MC-36).

(12) Ditongação: voceis por vocês (ROM-73), toudo por todo (ICO-48).

(13) Nasalização: muinta por muita (DCS-69).

(14) Palatalização: Brazilha por Brasília (GOR-28).

(15) Rotacismo: Dicurpi por desculpe (AFS-45).

(16) Lambdacismo: silvido por servido (NIN-38).

(17) Prótese: avoar por voar (ACO-44).

(18) Paragoge: veizi por vez. (AFS-24).

(19) Aférese: duentada por adoentada (ZSS-53).

(20) Síncope: nevozo por nervoso (JMA-64), pencanno por pensando (AFS-16).

(21) Apócope: chora por chorar (AHC-55).

(22) Metátese: porcura por procura (ZLS-70).

d) Repetição lexical: essa é uma estratégia básica de formulação da fala, e sua presença no corpus, como ilustra o exemplo (23), é um indício de que os documentos registram uma escrita próxima da oralidade.

(23) "Derta que eu mando u Dinheiro ou sirnão condo eu for eu leivo u Dinheiro nu dia 25 di Agosto eu vou mandar Dinheiro Par u sinhô" (Carta-14)

Alguns aspectos morfossintáticos também indicam o distanciamento dos modelos normativos e podem estar refletindo processos de variação da oralidade, como a variação na concordância nominal de número, exemplificadas em (24) e (25), e na concordância verbal, em (26) e (27):

(24) "São as horas mais filiz quando pego Nesta caneta para da minha noticias" (AHC-59)

(25) “abraco en toda as minha amigas que ainda selinbra de min" (MC-50)

(26) "eu posso colher as suas noticias que as minhas noticias ja vai" (JMS-66)

(27) "as couzas pur ca esta muito ruim que as aguas si acabou" (JMS-67)

Esse conjunto de propriedades, em vários planos, presente nos documentos, fornece pistas para reconhecer que os redatores são pouco familiarizados com o código escrito e a amostra é representativa da vertente popular do português. Além disso, verifica-se que traços de inabilidade já identificados em textos de séculos anteriores são aplicáveis a manuscritos desse período.

\section{SOBRE A BUSCA PELO PERFIL SÓCIO-CULTURAL DOS REDATORES}

Para a constituição de corpora apropriados aos estudos linguísticos sócio-históricos, é importante, segundo Mattos e Silva (2002, p. 23), a identificação de quem escreveu os documentos, quando, onde e para quem foram escritos, o que é uma difícil tarefa, segundo a autora. No âmbito da História da Cultura Escrita, essa também é uma proposta de Petrucci (2003, p. 7-8), ao apresentar um conjunto mínimo de questões que devem ser respondidas, para qualquer tempo histórico: o quê? Em que consiste o texto escrito; quando e onde? Época e lugar em que o texto foi escrito; como? Quais técnicas, instrumentos, materiais e modelos utilizados; quem? Ambiente sociocultural a que pertencia o redator e ambiente da difusão social da escrita, na época; para que o texto foi escrito? Qual era a finalidade do texto e qual poderia ser, em sua época e lugar, a finalidade ideológica e social da escrita. 
O acervo constituído pelas cartas dos sertanejos baianos corresponde ao que se espera de um corpus apropriado a estudos desse tipo, já que é possível reunir informações sobre aspectos vinculados ao perfil social dos redatores e destinatários, inclusive sobre seus processos de letramento.

Então, a construção do perfil biográfico de quem escreveu e recebeu as correspondências se deu a partir de conversas com alguns destinatários, remetentes e seus familiares - dos 55 remetentes e destinatários, 26 estão vivos. Também foram consultados documentos pessoais de alguns remetentes, e informações relevantes foram encontradas nas próprias cartas. Os primeiros diálogos ocorreram ainda no período de constituição do corpus, quando foram realizadas algumas visitas às casas de destinatários, onde estava arquivada boa parte dos documentos, como a fazenda Pau de Colher (54 cartas), em Riachão do Jacuípe, e a fazenda Cachorrinha (14 cartas), em Conceição do Coité. Os moradores forneceram valiosas informações sobre quem e para quem as cartas foram enviadas, além de possibilitarem o acesso às fotografias da família, importantes na reconstituição do passado.

Os dados foram organizados em fichas, conforme o exemplo a seguir ${ }^{2}$ :

Quadro 1 - Exemplo de ficha de remetente

\section{REMETENTE $\mathbf{N}^{\circ} 01$ \\ DADOS PESSOAIS}

Nome (conforme a carta): Antonio Fortunato da Silva.

Nome completo: Antonio Fortunato da Silva.

Filiação: José Vitorino de Souza e Maria Conceição da Silva.

Avós paternos/maternos: Antonio Brás Souza e Antonia Brás Souza/José Zeferino da Silva e Angélica Zeferino da Silva.

Naturalidade: Faz. Varjota, município de Riachão do Jacuípe, BA (1). Nacionalidade: Brasileira.

Data de nascimento: 06 de setembro de 1936.

Idade do remetente (quando da escrita da carta): 20 a 29 anos (da primeira à última carta, respectivamente).

Estado civil: Casado com Gertrudes. Atualmente é casado com Maura Ribeiro da Silva.

Escolaridade: Não frequentou a escola (2).

Principais atividades: Lavrador. Passou uma temporada em São Paulo trabalhando como ajudante.

Observações: (01) Morou durante algum tempo na fazenda Carrancudo, distrito de Mairi, BA. Em 1958, ele esteve em Ribeirão Preto, SP, para servir ao Exército e, em 1961, voltou para São Paulo, para trabalhar, onde viveu até 1965. Depois também morou em Mundo Novo, BA. Atualmente mora em Riachão do Jacuípe, BA. A maior parte das cartas escritas por ele corresponde ao período que residia em São Paulo.

(02) Antonio Fortunato afirma que não frequentou a escola e não teve aulas em casa, sua mãe era analfabeta e não tinha condições financeiras para pagar aulas particulares. Argumenta que aprendeu a escrever convivendo com amigos já escolarizados. Desde cedo lia a Bíblia. Atualmente é membro de uma Igreja Evangélica.

Fontes: Depoimentos concedidos por João Carneiro de Oliveira e Almerinda Maria Oliveira nos dia 05 de setembro de 2010 e 30 de janeiro de 2011. Depoimento concedido por Antonio Fortunato da Silva e Maura Ribeiro da Silva no dia 12 de março de 2011.

Fonte: Santiago (2012, p. 178).

As fichas registram diferentes informações sobre os remetentes e destinatários, contribuindo também na caracterização de quando e onde viveram/vivem e sobre o contexto em que escreveram as correspondências. O campo "Nome (conforme a carta)" tem a função de preservar a forma como o remetente se identifica na carta e, como às vezes ele usa uma alcunha e nem sempre aparece o seu nome completo, o segundo campo, "Nome completo", tem como propósito recuperar essa informação. As variantes etárias estão registradas nos itens: "Data de nascimento", "Data de falecimento" e "Idade do remetente (quando da escrita da carta)". A informação relativa à "Escolaridade" é bastante útil, no sentido de que

2 O modelo de ficha utilizado foi adaptado de Carneiro (2005). 
pode dar pistas sobre o acesso ou não às instituições de ensino, o que pode ser relacionado ao nível de letramento de cada redator/leitor. A ocupação está indicada em "Principais atividades" e, em "Observações", registra-se, quando necessário, informações adicionais que servem para confirmar ou inferir quaisquer dos itens da ficha. Por fim, são indicadas as "Fontes" utilizadas na pesquisa sobre cada um. O conjunto das informações sobre o perfil biográfico dos redatores/leitores das cartas acompanha a edição dos documentos, disponibilizada em Santiago (2012).

Muitas das informações que não foram obtidas durante essa etapa inicial do trabalho podem ser recuperadas durante o processo de produção de narrativas do passado, que ampliam significativamente as possibilidades de caracterização do contexto social da época, principalmente em relação às práticas sociais de escrever e de ler, interesse maior para o estudo do corpus em questão, uma vez que os sertanejos tiveram pouco ou nenhum acesso à escolarização formal ${ }^{3}$.

A opção pelas histórias de vida como meio para obtenção de indícios do perfil sociocultural dos sertanejos e, consequentemente, da penetração/difusão da língua escrita na zona rural do semiárido baiano, inspira-se, em grande parte, na abordagem (auto)biográfica ${ }^{4}$, com o uso de entrevistas narrativas, e também nos princípios metodológicos do Museu da Pessoa ${ }^{5}$ que desenvolve projetos a partir de uma metodologia que pressupõe ser a narrativa de cada pessoa a expressão de sua singularidade: "cada entrevistado não é entendido como uma mera fonte de 'informações' sobre o assunto, mas sim como uma pessoa que, de alguma maneira, vivenciou um pedaço de um momento histórico e se apropriou de forma pessoal de sua experiência" (WORCMAN, 2014, p. 151).

O planejamento da entrevista, com a elaboração de um roteiro prévio, tem a função apenas de fornecer apoio ao pesquisador, já que no decorrer da narrativa podem surgir outros temas ou alguns podem não ser mencionados, a depender do fluxo da conversa. Esse roteiro apresenta alguns temas, estabelecidos a partir do desejo de conhecer memórias/lembranças sobre as práticas de escrita e leitura constituídas no cotidiano dos sujeitos:

a) A infância/juventude: onde viveu, primeiros aprendizados, relação com os pais, saberes construídos nesse período.

b) A oralidade: contação de histórias, tipos de histórias, quem contava, onde, quando.

c) A aprendizagem da escrita: sobre como se deu esse aprendizado, relação dos pais com a escrita, presença de professores/escolas na região, a escrita das cartas.

d) A leitura: gosto pela leitura, presença de materiais de leitura em casa, maneiras de ler.

As narrativas fornecem indícios de que, durante o século XX, principalmente na primeira metade, período que corresponde à infância ou adolescência da maior parte dos remetentes/destinatários das cartas, na zona rural da Bahia, o processo de garantia do letramento através da criação e do funcionamento efetivo de escolas ainda ocorria com pouca frequência, mesmo que, nessa mesma época, nas cidades, ocorra um crescimento da preocupação com a escolarização da população. As poucas escolas que existiam, na região, funcionavam de modo precário, muitas vezes com professoras itinerantes.

De modo geral, os redatores e destinatários das cartas são lavradores, com baixas condições financeiras, trabalham com agricultura e criação de animais (principalmente os de

\footnotetext{
${ }^{3}$ As narrativas dos sertanejos baianos, assim como as 91 cartas pessoais, são fontes utilizadas na tese de doutorado, em andamento, de Santiago (Programa de Pós-Graduação em Língua e Cultura/UFBA), sob orientação da Profa. Dra. Zenaide de O. Novais Carneiro e coorientação do Prof. Dr. Afrânio G. Barbosa.

${ }^{4}$ A Associação Brasileira de Pesquisa (Auto)Biográfica tem difundido o uso da entrevista narrativa como uma importante fonte de coleta de dados, possibilitando interpretações acerca das trajetórias de vida (Cf. SOUZA, 2015).

${ }^{5}$ Cf. www.museudapessoa.net.
} 
pequeno porte); viviam, naquele período, distante dos centros urbanos, com poucos meios de transportes. O envolvimento com o trabalho rural pode ser notado mesmo com relação àqueles que foram trabalhar nas grandes cidades, em outras regiões do país, como São Paulo e Brasília, mas continuaram envolvidos com a vida na roça. Em termos de pouca habilidade com a escrita, não há muita diferença entre aqueles que não frequentaram uma instituição de ensino e os que estudaram os primeiros anos, ou seja, todos os remetentes, independente de como tiveram acesso às primeiras letras, apresentam, nos manuscritos, aspectos próprios a adultos em fase de aquisição da escrita.

Muitas vezes, a própria casa ou a de parentes serviu como espaço de aprendizagem e, para aqueles que não vivenciaram nem mesmo esses ambientes domésticos, com professoras que tiveram uma presença passageira na região ou com os próprios pais, o contato com alguns raros materiais de leitura, como os textos religiosos, pode ter contribuído para a aquisição da escrita.

O processo de migração também colaborou para isso, já que a necessidade de manter comunicação com os familiares e amigos que ficaram no sertão motivou os sertanejos, que viajaram para as grandes cidades em busca de trabalho, a produzirem cartas, de modo que muitas correspondências foram emitidas de São Paulo, centro industrial da época, e algumas de Brasília, durante a construção dessa cidade. Nesses casos, a distância dos que ficaram na terra natal foi decisiva para que, mesmo sem domínio da escrita, os sertanejos enviassem cartas escritas a próprio punho.

\section{CONSIDERAÇÕES FINAIS}

A localização das cartas de mãos inábeis mostra ser possível encontrar fontes mais transparentes aos traços de oralidade, o que permite uma reconstrução sócio-histórica e linguística mais aproximada do português popular brasileiro, a partir de textos escritos por um grupo excluído historicamente que, ao longo do tempo, esteve às margens do processo de escolarização. A inabilidade dos que escreveram, em maior ou menor grau, é evidenciada em propriedades coincidentes, em vários planos, nos manuscritos, vinculadas ao controle do perfil social daqueles que escreveram.

Nas próximas etapas do trabalho, pretende-se esboçar uma proposta metodológica, estabelecendo um contínuo, para a identificação dos níveis de inabilidade em corpora diacrônicos. Além disso, a partir das narrativas dos sertanejos, será possível estudar/conhecer melhor os indícios dos processos de letramento que caracterizaram a difusão da língua escrita na zona rural do semiárido da Bahia.

\section{REFERÊNCIAS}

BARBOSA, A. G. Fontes escritas e história da língua portuguesa no Brasil: as cartas de comércio no século XVIII. In: LIMA, I. S.; CARMO, L. do (Org.). História social da língua nacional. Rio de Janeiro: Edições Casa de Rui Barbosa, p. 181-211, 2008. Disponível em: $<$ www.casaruibarbosa.gov.br/dados/DOC/artigos/a-

j/FCRB_Historia_social_da_lingua_nacional.pdf>. Acesso em 04 abr. 2015.

BARBOSA, A. G. Para uma história do português colonial: aspectos linguísticos em cartas do comércio. 1999. 484f. Tese (Doutorado em Língua Portuguesa) - Faculdade de Letras, Universidade Federal do Rio de Janeiro, Rio de Janeiro, 1999. 
CARNEIRO, Z. de O. N. Cartas brasileiras (1808-1904): um estudo linguístico-filológico. 2005. 4v. 2.329f. Tese (Doutorado em Linguística) - Instituto de Estudos da Linguagem, Universidade Estadual de Campinas, Campinas, São Paulo, 2005.

CARNEIRO, Z. de O. N.; SANTIAGO, H. da S.; OLIVEIRA, K. (Org.). Cartas brasileiras (1809-2000): coletânea de fontes para o estudo do português. Vol. 3. 1. ed. Feira de Santana: UEFS Editora, 2011.

CE-DOHS: Corpus eletrônico de documentos históricos do sertão. Disponível em: [www.uefs.br/cedohs]. 2011.

MARQUILHAS, R. A faculdade das letras: leitura e escrita em Portugal no séc. XVII. Lisboa: Imprensa Nacional-Casa da Moeda, 2000.

MATTOS E SILVA, R. V. Caminhos da linguística histórica - "ouvir o inaudível”. São Paulo: Parábola Editorial, 2008.

MATTOS E SILVA, R. V. (Org.). Para a história do português brasileiro: primeiros estudos. São Paulo: Humanitas/FFLCH/USP/FAPESP, 2001. p. 553-555, t. II.

MATTOS E SILVA, R. V. Reflexões e questionamentos sobre a constituição de corpora para o projeto Para a história do português brasileiro. In: DUARTE, M. E. L.; CALLOU, D. (Org.). Para a história do português brasileiro - Notícias de corpora e outros estudos. v. 4. Rio de Janeiro: Faculdade de Letras da UFRJ/FAPERJ, 2002. p. 17-28.

OLIVEIRA, K. Ajuntamento de fontes para a história do português popular brasileiro: amores, desamores e outras espécies de dores. In: OLIVEIRA, K.; SOUZA, H. F. C.; GOMES, L. (Org.). Novos tons de Rosa... para Rosa Virgínia Mattos e Silva. Salvador: EDUFBA, 2009. p. 175-195.

OLIVEIRA, K. Negros e escrita no Brasil do século XIX: sócio-história, edição filológica de documentos e estudo linguístico. 2006. 3v. 1144f. Tese (Doutorado em Letras) - Instituto de Letras, Universidade Federal da Bahia, Salvador, 2006.

PETRUCCI, A. Escrituras marginales y escribientes subalternos. Signo. Revista de Historia de la Cultura Escrita. Universidad de Alcalá, n.7, p. 67-75, 2000.

PETRUCCI, A. La ciencia de la escritura: primera lección de paleografía. Buenos Aires: Fondo de Cultura Económica de Argentina, 2003.

SANTIAGO. H. da S. Um estudo do português popular brasileiro em cartas pessoais de "mãos cândidas" do sertão baiano. 2012. 2v. 421 f. Dissertação (Mestrado em Estudos Linguísticos) - Programa de Pós-graduação em Estudos Linguísticos, Universidade Estadual de Feira de Santana, Feira de Santana, 2012.

SOUZA, E. C. (Org.). (Auto)biografias e documentação narrativa: redes de pesquisa e formação. Salvador: EDUFBA, 2015.

WORCMAN, K. Narrativas digitais: eu, nós e quem mais? A relação ente histórias de vida e museus digitais. In: OSWALD, M. L. M. B.; JUNIOR, D. R. do C.; WORCMAN, K. (Org.). Narrativas digitais, memórias e guarda. Curitiba, PR: Editora CRV, 2014. p. 145-155. 